\title{
ORIGINAL ARTICLE CHARACTERISTICS AND OUTCOMES OF ROTATIONAL ATHERECTOMY IN A TERTIARY CARE CARDIOLOGY FACILITY IN PAKISTAN
}

\author{
Bilal Kabeer Khan', Osman Faheem ${ }^{1}$, Muhammad Nasir Rahman' \\ ${ }^{1}$ Aga Khan University Hospital, Karachi, Pakistan
}

\begin{abstract}
Objectives: To retrospectively review the short term outcomes of rotational atherectomy in a high CathPCI Risk and high Syntax Population.

Methodology: A total of 51 patients who underwent RA between $1^{\text {st }}$ June 2017 and $31^{\text {st }}$ April 2019 were retrospectively reviewed after approval from ethical review committee. Clinical follow up was obtained for procedural success and major adverse cardiovascular events (MACE) at 3 months.

Results: Patients who underwent RA were high risk with a mean Syntax score $32.7 \pm 5.9$ and mean NCDR CathPCI risk score of $51.1 \pm 13$. The mean age of the patients were 70 years, majority were males $(81 \%)$, type 2 diabetics $(78 \%)$ with chronic kidney disease $(52.7 \%)$, NonST elevated myocardial infarction (NSTEMI) (35\%) and Syntax Score $>32$ (64.8\%). Out of 37 individuals, procedural success was reported in all subjects except one in the high risk syntax group. At three months, MACE was reported in 4 patients. Out of these four, one was intraprocedural death, three had repeat myocardial infarction. Out of these three, two declined repeat revascularization and were managed medically. One patient died during admission despite repeat revascularization. Almost all MACE reported, occurred in patients with Syntax $>32$.

Conclusion: Despite high risk Syntax and CathPCI scores, RA led to high immediate procedural success for PCI in calcified lesions at our hospital with infrequent MACE.

Keywords: Atherectomy, Directional/Rotational; Percutaneous Coronary Intervention (PCI), Coronary Artery Disease

Citation: Khan BK, Faheem O, Rahman MN. Characteristics and Outcomes of Rotational Atherectomy in a Tertiary
Care Cardiology Facility in Pakistan. Pak Heart J. 2021;54(03):214-218. DOI:

https://doi.org/10.47144/phj.v54i3.2166
\end{abstract}

\section{INTRODUCTION}

Coronary artery calcification (CAC) is a common finding on angiogram that increases the complexity of percutaneous coronary interventions (PCI). ${ }^{1}$ Calcified lesions pose a higher risk of post-PCI complications due to stent under-expansion and mal-apposition as compared to lesions with minimal or no calcium. ${ }^{2}$ $\mathrm{CAC}$ has a strong association with increasing age and male gender. Around $90 \%$ of males over the age of 70 years have $\mathrm{CAC} .^{3} \mathrm{~A}$ recent retrospective analysis of a large multiethnic cohort undergoing PCI with drug eluting stents concluded that CAC remained an independent predictor of post PCI complications. ${ }^{4}$ In this study major adverse cardiovascular events (MACE) among patients with none/mild, moderate, and severe calcification were 8.3, 14.6, and $17.8 \%$, respectively. ${ }^{4}$ Mechanical debulking of lesions with rotational atherectomy (RA) is essential in managing these calcified lesions. ${ }^{5,6}$ RA involves differential sanding of calcified coronary plaques with the use of diamond tip rotablator device (Boston Scientific, USA) that is advanced over a guide wire at 140,000 to 180,000 revolutions per minute. ${ }^{7}$ Evidence of RA from the US and Europe is extensive, however, little has been published from lower middle income countries (LMIC). Evidence from ROTAXUS (Rotational Atherectomy Prior to TAXUS Stent Treatment for Complex Native Coronary Artery Disease) study performed in mainly Caucasian patients showed that despite high immediate success (92\%), there was no effect of rotational atherectomy on late lumen loss and recurrent cardiac events. At two years follow up there was no difference in outcomes between patients undergoing PCI with or without RA. ${ }^{8,9}$ G Minocha et al. reported a procedural success rate of $99 \%$ in Indian patients with MACE reported in 8\% patients whereas Baruah DK et al. concluded in Indian patients that the procedural success rates approached $97.8 \%$ and MACE was $8 \%$.This is much lower than the MACE rate of $28 \%$ at 9 months and $29 \%$ at 2 years reported by ROTAXUS. A review of these South Asian studies also show that the predominant presentation was acute coronary syndrome (ACS) which is in contrast to ROTAXUS where the predominant presentation was stable angina. The mean burr size used was also smaller. ${ }^{10,11}$ Data regarding RA from Pakistan is absent. Outcomes and characteristics of RA in our patients are expected to differ due to increased age, frailty, multiple co-morbidities, complex lesions, 
genetics, environmental factors and resource limitation. Many of our patients presenting for rotablation have prohibitive surgical risk. We need to study if the difference in outcomes between ROTAXUS and Indian studies are reflected in our patients as well. This study is also an effort to put forward our experience of RA assisted PCI.

\section{METHODOLOGY}

A retrospective chart review was conducted at the Aga Khan University Hospital Karachi (AKUH, K), after approval from the hospital ethics review committee and conforms to national regulations. The Health Information Management Services at AKUH, K maintains comprehensive, updated hybrid patient medical records, integrating both paper and electronic records. After approval from the hospital ethics review committee, we retrospectively reviewed all PCI cases performed at AKUH, K between $1^{\text {st }}$ June 2017 and $31^{\text {st }}$ April 2019 from our cardiac catheterization lab records and identified patients who required atherectomy with rotablator device (Boston Scientific, USA) prior to PCI. We subsequently reviewed their medical records and angiograms. Through this review process we noted baseline, angiographic and procedural characteristics along with study outcomes. Angiographic complexity was recorded using Syntax score whereas clinical risk was calculated using NCDR CathPCI risk score. ${ }^{12,13}$ The primary outcome of the study was immediate procedural success defined as residual stenosis less than 50 percent and TIMI (Thrombolysis in Myocardial Infarction) grade III flow after coronary intervention in target vessel. The secondary outcomes are MACE at 3 months defined as composite of (1) death from any cause, (2) myocardial infarction; defined as greater than 5-fold elevation of troponin I, new pathological Q-waves on ECG or angiographic findings of a flow -limiting coronary occlusion and (3) target lesion revascularization; defined as percutaneous intervention, or bypass surgery performed because of restenosis of the target lesion. ${ }^{14,15}$ All adult patients aged 18 years of age or more, who underwent RA assisted PCI in the last 2 years at AKUH were retrospectively reviewed and clinical follow up obtained for procedural success and MACE at three months. For the purpose of study, patients who had undergone RA assisted PCI were identified. Information relevant to study objectives was collected using a predesigned proforma. The information regarding outcomes and MACE was collected from review of charts. The data was analyzed using SPSS V20.0 and results were expressed in terms of means and standard deviation for quantitative variables and percentages for qualitative variables.

\section{RESULTS}

The mean age of the patients was $70.1 \pm 9$ years. Out of 51 patients, $41(82 \%)$ were males, $40(78.4 \%)$ were diabetics and $45(88.2 \%)$ were hypertensive. Out of 51 patients 21 (41.1\%) had prior MI and $29(56.8 \%)$ patients had left ventricular systolic dysfunction (left ventricular ejection fraction $\leq 40 \%)$. The most common presentation was angina $28(54.9 \%)$ followed by NSTEMI $18(35.2 \%)$ and ST-elevation myocardial infarction (STEMI) 3 (5.8\%). The baseline characteristics of patients are summarized in Table 1.

Table 1: Baseline Characteristics

\begin{tabular}{|l|c|}
\hline Characteristics & N (\%)/Mean \pm SD \\
\hline Total Patients & $\mathbf{N = 5 1}$ \\
\hline Age in years & $70.1 \pm 9$ \\
\hline Males & $41(82 \%)$ \\
\hline Diabetes & $40(78.4 \%)$ \\
\hline Hypertension & $45(88.2 \%)$ \\
\hline Dyslipidemia & $30(58.8 \%)$ \\
\hline Smoking & $21(41.1 \%)$ \\
\hline Chronic Kidney Disease & $19(37.2 \%)$ \\
\hline Hemodialysis & $8(15.6 \%)$ \\
\hline Left ventricular Dysfunction & $29(56.8 \%)$ \\
\hline STEMI & $3(5.8 \%)$ \\
\hline NSTEMI & $18(35.2 \%)$ \\
\hline Angina & $28(54.9 \%)$ \\
\hline Cardiogenic Shock & $2(3.9 \%)$ \\
\hline Prior MI & $21(41.1 \%)$ \\
\hline Prior PCI & $7(13.7 \%)$ \\
\hline Prior CABG & $10(19.6 \%)$ \\
\hline
\end{tabular}

STEMI=ST- elevation myocardial infarction, NSTEMI=Non ST elevated myocardial infarction, MI=myocardial infarction, $P C I=$ percutaneous coronary intervention, $C A B G=$ coronary artery bypass grafting

In the majority of patients, target lesion for RA was located in the left anterior descending artery (LAD) 36 $(70.5 \%)$, followed by the left main coronary artery (LMCA); 12 (23.5\%). The mean length of the lesions rotablated was $36.41 \pm 14.5 \mathrm{~mm}$. Of all the lesions rotablated, $16(31.3 \%)$ were bifurcation lesions. All patients with left main disease or three vessel disease with Syntax score $>22$, consulted a cardiothoracic surgeon prior to procedure. The mean Syntax score was $32.7 \pm 5$. A total of $34(66.6 \%)$ patients had a Syntax score $>32$ at the time of presentation. Our patients had a significantly high mortality risk and complex coronary lesions as depicted by a mean NCDR CathPCI risk score of $51.1 \pm 13$ and a mean Syntax score $32.7 \pm 5.9$ respectively. The angiographic characteristics of patients are presented in Table 2 .

A pre-procedure temporary pacemaker was placed in $44(86.2 \%)$ patients but only $11(21.6 \%)$ needed to be retained post-procedure. The mean burr size used was $1.5 \mathrm{~mm} \pm 0.2$. A single burr was used in $50(98.0 \%)$ 
patients and the mean number of vessels rotablated per patient was $1.27 \pm 0.45$. No reflow was noted in 3 $(5.9 \%)$ patients and inotropes were required in 21 $(56.7 \%)$. The mean volume of contrast used was $246.62 \pm$ 112.3. Intravascular ultrasound was performed in $7(13.7 \%)$ and all 51 patients received drug eluting stents (DES).

Table 2: Angiographic and Procedural Characteristics of Patients Undergoing Rotational Atherectomy

\begin{tabular}{|l|c|}
\hline Characteristics & N (\%)/Mean \pm SD \\
\hline Total Patients & $\mathbf{N = 5 1}$ \\
\hline Target lesion location (Vessel) & $12(23.5 \%)$ \\
\hline Left Main & $36(70.5 \%)$ \\
\hline LAD & $11(21.5 \%)$ \\
\hline LCX & $8(15.6 \%)$ \\
\hline RCA & $36.41 \pm 14.5 \mathrm{~mm}$ \\
\hline Target lesion length & $16(31.3 \%)$ \\
\hline Bifurcation Lesions n (\%) & $5(9.8 \%)$ \\
\hline Syntax score & $12(23.5 \%)$ \\
\hline$<22$ & $34(66.6 \%)$ \\
\hline $22-32$ & $32.7 \pm 5.9$ \\
\hline$>32$ & $51.1 \pm 13$ \\
\hline Mean Syntax Score & $44(86.2 \%)$ \\
\hline Mean CathPCI Score & $11(21.6 \%)$ \\
\hline TPM placed & $1.5 \pm 0.2$ \\
\hline TPM retained & $50(98.0 \%)$ \\
\hline Burr size in mm & $1(1.9 \%)$ \\
\hline Number of burrs & $3(5.9 \%)$ \\
\hline 1 burr & $1(2.7 \%)$ \\
\hline 2 burr & $21(1.9 \%)$ \\
\hline No reflow & $1.27 \pm 0.45$ \\
\hline Intra-aortic balloon pump & $246.62 \pm 112.3$ \\
\hline Inotropes & $7(13.7 \%)$ \\
\hline Total vessels rotablated & \\
\hline Contrast used in ml & \\
\hline Intravascular Ultrasound & \\
\hline
\end{tabular}

$S T E M I=S T$ - elevation myocardial infarction, NSTEMI=Non $S T$ elevated myocardial infarction, MI=myocardial infarction, $P C I=$ percutaneous coronary intervention, $C A B G=$ coronary artery bypass grafting

Overall, amongst 37 individuals, procedural success was reported in $50(98.0 \%)$ subjects; $33(97.0 \%)$ in Syntax $>32$ and $17(100 \%)$ in Syntax $<32$ (Table 3$)$. At three months, MACE was reported in $5(9.8 \%)$ patients. Two patients $(5.4 \%)$ died. All these events were reported in patients with Syntax $>32$ group. Out of these one was intra-procedural death whereas one patient died in the coronary care unit despite repeat revascularization after being readmitted for NSTEMI. In all, three patients $(8.1 \%)$ experienced another MI in 3 months; two of these declined repeat revascularization and were managed medically. Only one patient $(2.7 \%)$ underwent repeat revascularization with unfavorable final outcome as mentioned above. Almost all the events occurred in Syntax $>32$ subgroup where the proportion of MACE was $5(9.8 \%)$, death 2 (3.9\%), myocardial Infarction $3(5.8 \%)$ and target lesion revascularization 1 (1.9\%). In the Syntax <32 subgroup only one myocardial infarction was reported MACE (7.6\%) (Figure 1).

Table 3: Outcomes of Rotational Atherectomy

\begin{tabular}{|l|c|c|c|}
\hline \multirow{2}{*}{} & Overall & \multicolumn{2}{|c|}{ Syntax Score } \\
\cline { 2 - 4 } & Outcomes & $\mathbf{3 2}$ & $<\mathbf{3 2}$ \\
\hline $\begin{array}{l}\text { Immediate } \\
\text { Procedural Success }\end{array}$ & $\begin{array}{c}50 \\
(98.0 \%)\end{array}$ & $33(97.0 \%)$ & $17(100 \%)$ \\
\hline Major Adverse Cardiovascular Events At 3 months \\
\hline $\begin{array}{l}\text { Total Major Adverse } \\
\text { Cardiovascular } \\
\text { Events }\end{array}$ & $5(9.8 \%)$ & $5(9.8 \%)$ & $0(0 \%)$ \\
\hline Death & $2(3.9 \%)$ & $2(3.9 \%)$ & $0(0 \%)$ \\
\hline $\begin{array}{l}\text { Myocardial } \\
\text { Infarction }\end{array}$ & $3(5.8 \%)$ & $2(3.9 \%)$ & $1(1.9 \%)$ \\
\hline $\begin{array}{l}\text { Target Lesion } \\
\text { Revascularization }\end{array}$ & $1(1.9 \%)$ & $1(1.9 \%)$ & $0(0 \%)$ \\
\hline
\end{tabular}

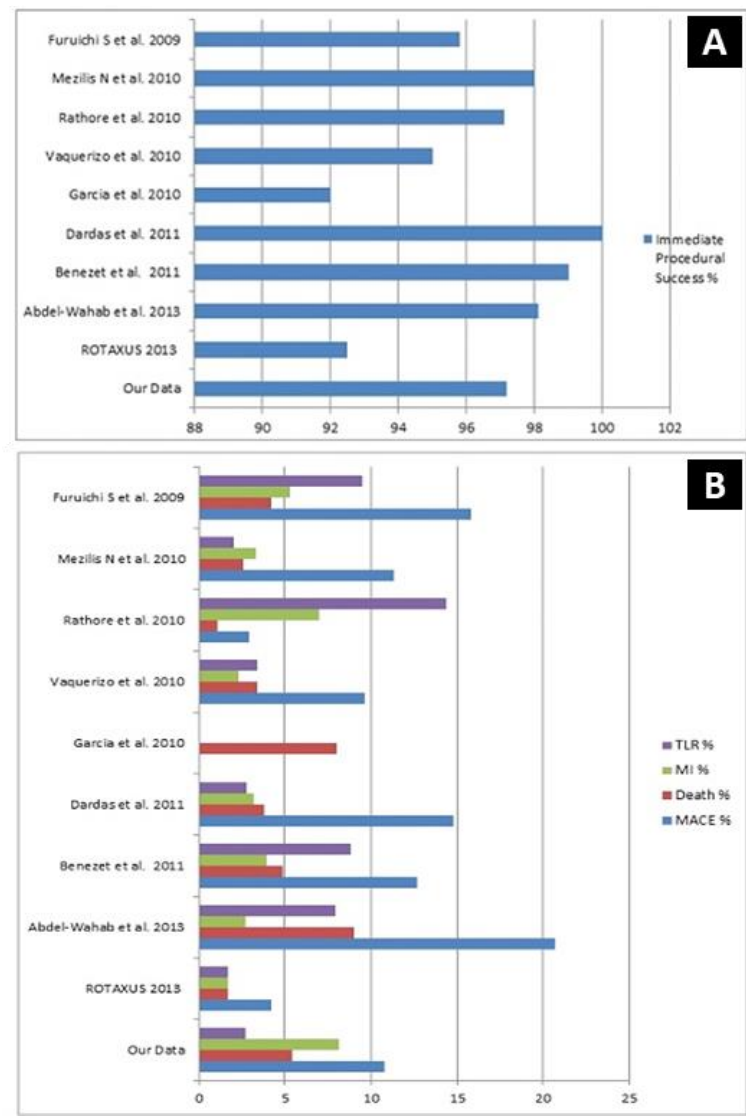

Figure 1: Comparison of procedural success (A) comparison of major adverse cardiovascular outcomes (B)

\section{DISCUSSION}

The European expert consensus document concludes that in the hands of experienced operators; rotablation is both safe and effective in the treatment of calcified lesions. ${ }^{16}$ Our procedural success was high and 
comparable to international data; despite significantly high risk clinical parameters, angiographic features. In contrast to previous South Asian data, majority of the patients had non-ACS presentation. Resource limitations led to the adoption of a predominant single burr strategy and limited use of intravascular imaging. We reported the highest mean Syntax score for any RA study so far. In our review of literature, we could not find any study on RA that examined the NCDR CathPCI risk scores of participants. Compared to ROTAXUS, our MACE rates were higher, however our patient population had more comorbidities and were at higher risk (Figure 1). ${ }^{8}$

The baseline characteristics (Table 1) of our patients were comparable with European data. A review of published literature shows that the mean age varies from 67-70.5 years and proportion of males were 68$86 \%$. The most common co-morbidities reported are hypertension, diabetes followed by dyslipidemia. In almost all studies, patients presented mainly with angina followed by NSTEMI. In comparison with previous studies, our patients had significantly high risk clinical parameters like LV dysfunction, current MI, high Syntax Score, LMCA interventions and acute coronary syndrome (ACS) presentation. The proportion of LV dysfunction (defined as LV ejection fraction $\leq 40 \%$ ) in previous literature was $25-32 \%$ and current MI (4-14\%). ${ }^{17-26}$ In our review of literature we did not come across a single study that looked into CathPCI risk scores of RA patients. Syntax Score, on the other hand has been extensively studied and is an important determinant of outcomes following RA. In one study, Syntax Score cut-off value of 15 had $73 \%$ sensitivity and $62 \%$ specificity for predicting inhospital adverse outcomes. ${ }^{25}$ Our mean Syntax score $(32.7 \pm 5)$ was higher than reported by previous authors (Table 1). The reason for this dissimilarity in patient population is that most of our RA patients had been either turned down for CABG by the surgical team or had refused surgery. The angiographic/procedural characteristics and procedural outcomes (Table 2) reflect this high mean Syntax score of participants. LMCA was the target vessel in 2.1-16.3\% in published literature whereas LAD is consistently; the most common vessel rotablated $(50-70 \%)$. The average length of the coronary lesions reported are 20.6-39 $\mathrm{mm}$. No-reflow or slow flow in our patients was higher than reported by Abdel-Wahab et Al. (1.9\%). ${ }^{17}$ This can be explained by the greater lesion length and larger proportion of ACS patients encountered; both of which are important risk factors for no reflow during RA. Previous investigators have reported a mean burr size of $1.5 \pm 0.2 \mathrm{~mm}$. Although in most cases we rotablated only a single vessel whereas Garcia et al. had reported a mean of $2.36 \pm 0.8$ vessels rotablated.
Contrast volume used is essential consideration during complex PCI. However, it has been seldom reported in rotational atherectomy studies. Only ROTAXUS had reported a mean volume of contrast at $201.0 \pm 113.6$ $\mathrm{ml}$. This is less than our study but can be explained by the higher risk and complex lesions encountered in our patients. ${ }^{8}$ IVUS is critical in ensuring stent expansion and apposition post rotablation. Our use of IVUS was limited by financial constraints to LMCA interventions only. Studies have reported a wide variation in IVUS use; from none in ROTAXUS to $96.5 \%$ by Rathore et al. ${ }^{8,22}$ Patients also significantly differed in the type of drug eluting stents deployed. We mainly used everolimus eluting stents whereas in previous studies, sirolimus and paclitaxel eluting stents were predominantly used. This simply reflects advancement in stent design and drug delivery, since sirolimus and paclitaxel eluting stents are now obsolete. , $^{17-24}$ Immediate procedural success after RA is usually high (Figure 1). Our procedural success rate was comparable to the success rates reported by multiple studies $(92-95 \%) .{ }^{17-24}$ In our review of literature we found only one paper by MH Chiang et.al that had reported rotablation outcomes in high Syntax scores and had reported nearly similar procedural success rate of $91.2 \%$ and MACE of $16.1 \% .{ }^{25}$ MACE after RA varies from study to study (Figure 1). The reason for this is that some studies like ROTAXUS had excluded certain high risk patient groups (ACS and LV dysfunction). ${ }^{8}$ Our MACE rates were comparable to Mezilis et al. (11.3\%). where a significant proportion of patients underwent LMCA rotablation. ${ }^{21}$ Our MACE rates were also comparable to Benezet et al. $(12.7 \%)$ where a large number of patients had ACS presentation. ${ }^{16}$

This study showed that RA assisted PCI at our institute had a high success rate despite the high risk substrate and limited resources. However, it has limitations due to its retrospective design, short follow up and limited sample size. To ascertain whether these results can be generalized to the entire population would require a multi-center prospective study.

\section{CONCLUSION}

Despite high risk Syntax and CathPCI scores, RA led to high immediate procedural success for percutaneous coronary intervention in calcified lesions with infrequent major adverse cardiovascular events. However, larger prospective studies are required to study the outcomes of RA in a LMIC with a high risk patient population.

\section{AUTHORS' CONTRIBUTION}

BKK: Concept and design, data acquisition, interpretation, drafting, final approval, and agree to be accountable for all aspects of the work. OF and MNR: 
Data acquisition, interpretation, drafting, final approval and agree to be accountable for all aspects of the work.

Conflict of interest: Authors declared no conflict of interest.

\section{REFERENCES}

1. Wong ND, Kouwabunpat D, Vo AN, Detrano RC, Eisenberg H, Goel M, et al. Coronary calcium and atherosclerosis by ultrafast computed tomography in asymptomatic men and women: relation to age and risk factors. Am Heart J. 1994;127(2):422-30.

2. Abazid RM, Obadah Kattea M, Smettei OA, Beshir Y, Sakr H. Impact of coronary artery calcification on percutaneous coronary intervention and postprocedural complications. J Saudi Heart Assoc. 2017;29(1):15-22.

3. Goel M, Wong ND, Eisenberg H, Hagar J, Kelly K, Tobis JM Risk factor correlates of coronary calcium as evaluated by ultrafast computed tomography. Am J Cardiol. 1992;70(11):977-80.

4. Fiorilli PN, Anwaruddin S. How Do We Treat Complex Calcified Coronary Artery Disease? Curr Treat Options Cardiovasc Med. 2016;18(12):72.

5. Madhavan MV, Tarigopula M, Mintz GS, Maehara A, Stone GW, Généreux P. Coronary artery calcification: pathogenesis and prognostic implications. J Am Coll Cardiol. 2014;63(17):1703-14

6. Lee MS, Park KW, Shlofmitz E, Shlofmitz RA. Comparison of rotational atherectomy versus orbital atherectomy for the treatment of heavily calcified coronary plaques. Am J Cardiol. 2017;119(9):1320-3.

7. Tomey MI, Kini AS, Sharma SK. Current status of rotational atherectomy. JACC Cardiovasc Interv. 2014;7(4):345-53.

8. Abdel-Wahab M, Richardt G, Joachim Büttner H, Toelg R, Geist $\mathrm{V}$, Meinertz T, et al. High-speed rotational atherectomy before paclitaxel-eluting stent implantation in complex calcified coronary lesions: the randomized ROTAXUS (Rotational Atherectomy Prior to Taxus Stent Treatment for Complex Native Coronary Artery Disease) trial. JACC Cardiovasc Interv. 2013;6(1):10-9.

9. de Waha S, Allali A, Büttner HJ, Toelg R, Geist V, Neumann FJ, et al. Rotational atherectomy before paclitaxel-eluting stent implantation in complex calcified coronary lesions: Two-year clinical outcome of the randomized ROTAXUS trial. Catheter Cardiovasc Interv. 2016;87(4):691-700.

10. Minocha G, Chugh S, Agarwal P. Rotational atherectomy with sirolimus-eluting stents in calcific lesions: Acute results and longterm outcomes. Indian Heart J. 2005;57:207.

11. Baruah DK, Panigrahi NK, Baruah N. Clinical Outcomes of Rotational Atherectomy in Calcified Coronary Artery Lesions in Drug-Eluting Stent Era: A Single Centre Experience. Interv Cardiol J. 2018;04(03):7.

12. Sianos G, Morel M-A, Kappetein AP, Morice M-C, Colombo A, Dawkins K, et al. The SYNTAX Score: an angiographic tool grading the complexity of coronary artery disease. EuroIntervention. 2005;1(2):219-27.

13. Peterson ED, Dai D, DeLong ER, Brennan JM, Singh M, Rao SV, et al. Contemporary mortality risk prediction for percutaneous coronary intervention: results from 588,398 procedures in the
National Cardiovascular Data Registry. J Am Coll Cardiol. 2010;55(18):1923-32

14. Thygesen K, Alpert JS, Jaffe AS, Chaitman BR, Bax JJ, Morrow DA, et al. Fourth universal definition of myocardial infarction (2018). Am Coll Cardiol. 2018;72(18):2231-64.

15. Reifart N, Vandormael M, Krajcar M, Göhring S, Preusler W, Schwarz F, et al. Randomized comparison of angioplasty of complex coronary lesions at a single center: Excimer Laser, Rotational Atherectomy, and Balloon Angioplasty Comparison (ERBAC) Study. Circulation. 1997;1;96(1):91-8.

16. Barbato E, Carrié D, Dardas P, Fajadet J, Gaul G, Haude M, et al. European expert consensus on rotational atherectomy. EuroIntervention. 2015;11(1):30-6.

17. Abdel-Wahab M, Baev R, Dieker P, Kassner G, Khattab AA, Toelg R, et al. Long-term clinical outcome of rotational atherectomy followed by drug-eluting stent implantation in complex calcified coronary lesions: Long-Term Outcome of RotaDES. Catheter Cardiovasc Interv. 2013;81(2):285-91.

18. Benezet J, Díaz de la Llera LS, Cubero JM, Villa M, FernándezQuero M, Sánchez-González A. Drug-eluting stents following rotational atherectomy for heavily calcified coronary lesions: longterm clinical outcomes. J Invasive Cardiol. 2011;23(1):28-32.

19. Dardas P, Mezilis N, Ninios V, Tsikaderis D, Theofilogiannakos EK, Lampropoulos S. The use of rotational atherectomy and drugeluting stents in the treatment of heavily calcified coronary lesions. Hellenic J Cardiol. 2011;52(5):399-406.

20. García de Lara J, Pinar E, Ramón Gimeno J, Hurtado JA, Lacunza $\mathrm{J}$, Valdesuso R, et al. Percutaneous coronary intervention in heavily calcified lesions using rotational atherectomy and paclitaxel-eluting stents: outcomes at one year. Rev Esp Cardiol. 2010;63(1):107-10

21. Vaquerizo B, Serra A, Miranda F, Triano JL, Sierra G, Delgado G, et al. Aggressive plaque modification with rotational atherectomy and/or cutting balloon before drug-eluting stent implantation for the treatment of calcified coronary lesions: Treatment of calcified coronary lesions. J Interv Cardiol. 2010;23(3):240-8.

22. Rathore S, Matsuo H, Terashima M, Kinoshita Y, Kimura M, Tsuchikane E, et al. Rotational atherectomy for fibro-calcific coronary artery disease in drug eluting stent era: procedural outcomes and angiographic follow-up results. Catheter Cardiovasc Interv. 2010;75(6):919-27.

23. Mezilis N, Dardas P, Ninios V, Tsikaderis D. Rotablation in the drug eluting era: immediate and long-term results from a single center experience: Rotablation in the drug eluting era. J Interv Cardiol. 2010;23(3):249-53.

24. Furuichi S, Sangiorgi GM, Godino C, Airoldi F, Montorfano M, Chieffo A, et al. Rotational atherectomy followed by drug-eluting stent implantation in calcified coronary lesions. EuroIntervention. 2009;5(3):370-4.

25. Chiang MH, Yi HT, Tsao CR, Chang WC, Su CS, Liu TJ, et al. Rotablation in the treatment of high-risk patients with heavily calcified left-main coronary lesions. J Geriatr Cardiol. 2013;10(3):217-25.

26. Mankerious N, Hemetsberger R, Traboulsi H, Toelg R, AbdelWahab M, Richardt G, et al. Predictors of in-hospital adverse outcomes after rotational atherectomy: Impact of the target vessel SYNTAX score. Cardiovasc Revasc Med. 2020;21(6):754-9.

\section{Address for Correspondence:}

Dr. Bilal Kabeer Khan, Fellow Interventional Cardiology, Aga Khan University Hospital, Karachi, Pakistan. Email: bilal.kabeer.khan@gmail.com 